\title{
LOAD DETERMINATION BY ANALYSING THE STRESS STATE FOR THE OPEN-DIE FORGING OF THE ALUMINIUM ALLOY AlMgSi0.5
}

\author{
DOLOČANJE OBREMENITVE Z ANALIZO NAPETOSTNEGA \\ STANJA PRI PROSTEM KOVANJU ALUMINIJEVE ZLITINE \\ $\mathrm{AlMgSi} 0,5$
}

\author{
Mileta Janjić, Milan Vukčević, Nikola Šibalić, Sreten Savićević \\ University of Montenegro, Faculty of Mechanical Engineering, Cetinjska 2, 81000 Podgorica, Montenegro \\ mileta@ac.me \\ Prejem rokopisa - received: 2016-05-19; sprejem za objavo - accepted for publication: 2016-06-03
}

This paper deals with the stress state for the open-die forging of a staggered axial-symmetric specimen of the aluminium alloy AlMgSi0.5. The experimental-theoretical method of visioplasticity, adjusted for the process of open-die forging, consisted of five steps. The basic equations of the plasticity theory, i.e., balance equation, conditions of a plastic flow and Levy-Mises equations are applied. The basic partial differential equations of visioplasticity are obtained theoretically, while the displacement of points of the meridian cross-section, which represents the basis for its solution, can be experimentally obtained. The deformation force is calculated on the basis of the obtained results and is compared to the experimental values.

Keywords: visioplasticity, strain rate, stress, deformation force, displacement, tensor

Članek obravnava napetostno stanje pri prostem kovanju stopničastega osnosimetričnega vzorca iz aluminijeve zlitine AlMgSi0,5. Eksperimentalno-teoretična metoda, prilagojena postopku prostega kovanja, je setavljena iz petih korakov. Uporabljena je bila osnovna enačba teorije plastičnosti: ravnotežna enačba, pogoji plastičnega tečenja in Levy-Misesove enačbe. Osnovna parcialna diferencialna enačba vizioplastičnosti je dobljena teoretično, medtem ko se premik meridiana prečnega preseka, kar predstavlja osnovo za njeno rešitev, lahko dobi eksperimentalno. Sila deformacije je izračunana na osnovi dobljenih rezultatov in je primerjana $\mathrm{z}$ eksperimentalno dobljenimi vrednostmi.

Ključne besede: vizioplastičnost, raztezek, trgalna hitrost, napetost, sila deformacije, premik, tenzor

\section{INTRODUCTION}

The use of numerical methods for the deformation parameters' calculation is constantly being enhanced by the increment of simplicity of usage, the development of advanced software, reducing the time for the preparation of input data and obtaining of a wide spectrum of output information. Beside this, the questions asking whether the entry data were correctly taken and are the obtained results valid always are being raised. ${ }^{1,2}$ For this purpose, it is necessary to develop or adapt the experimental-theoretical methods serving to verify the numerically obtained results. ${ }^{1,3}$ There were many attempts by several authors to determine the stress state for a volumetric deformation, such as setting of a mesh at the specimen's cross-section before the deformation and a comparison with a deformed mesh, ${ }^{4-6}$ determination of a deformed image of the cross-section after the deformation process ${ }^{7,8}$ use of the Upper Bound Elemental Technique (UBET), ${ }^{9}$ etc.

One of the methods for the determination of the stress state is the visioplasticity method..$^{10,11}$ This is an experimental-theoretical method based on the known kinematic parameters of the deformation process. This method enables the analysis of plane and axial-symmetric problems in the processing by deformation. The method uses the basic equations of the theory of plasticity: balance equations, conditions of a plastic flow and equations by Levy-Mises.

The procedure of the calculation of the tensor stress components by the visioplasticity method can be divided into five steps:

- Deformation of the specimen and preparation for the reading of point displacements of the meridian cross-section,

- Determination of the strain tensor components,

- Determination of the strain rate tensor components,

- Solution of the basic equation for visioplasticity,

- Determinations of stress tensor components.

There are three different variants of this method. The differences are conditioned by the deformation processes and the manner of the experimental determination of displacements of points of a specimen's cross-section. This paper presents the originally adjusted method of visioplasticity, adjusted to open-die forging. 
M. JANJIĆ et al.: LOAD DETERMINATION BY ANALYSING THE STRESS STATE FOR THE OPEN-DIE FORGING ...

\section{THEORETICAL BASICS}

\subsection{Stresses}

The stress tensor for an axial-symmetrical problem has the following shape: $\left(\tau_{\mathrm{r} \theta}=\tau_{\theta \mathrm{z}}=0\right):^{12}$

$$
T_{\sigma}=\left|\begin{array}{ccc}
\sigma_{r} & 0 & \tau_{r z} \\
0 & \sigma_{\theta} & 0 \\
\tau_{r z} & 0 & \sigma_{z}
\end{array}\right|
$$

and the balance equations are:

$$
\left.\begin{array}{c}
\frac{\partial \sigma_{r}}{\partial r}+\frac{\partial \tau_{r z}}{\partial z}+\frac{\sigma_{r}-\sigma_{\theta}}{r}=0 \\
\frac{\partial \tau_{r z}}{\partial r}+\frac{\partial \sigma_{z}}{\partial z}+\frac{\tau_{r z}}{r}=0
\end{array}\right\}
$$

The effective stress [42,67] is:

$\sigma_{e}=\frac{1}{\sqrt{2}} \sqrt{\left(\sigma_{r}-\sigma_{\theta}\right)^{2}+\left(\sigma_{\theta}-\sigma_{r}\right)^{2}+\left(\sigma_{r}-\sigma_{z}\right)^{2}+6 \tau_{r z}^{2}}$

and the average normal stress is equal to:

$$
\sigma_{a}=\frac{1}{3}\left(\sigma_{r}+\sigma_{\theta}+\sigma_{z}\right)
$$

The stress intensity has major importance in the theory of plastic flow because on the basis of the biggest deformation energy spent for the shape change, an elementary part changes from the elastic into plastic state when the stress intensity reaches the boundary value. From (3), it follows that:

$$
\left(\sigma_{r}-\sigma_{\theta}\right)^{2}+\left(\sigma_{\theta}-\sigma_{r}\right)^{2}+\left(\sigma_{r}-\sigma_{z}\right)^{2}+6 \tau_{r z}^{2}=2 \sigma_{e}^{2}
$$

which represents the condition of plastic flow for an axial-symmetric stress state.

\subsection{Strain}

There is no displacement in the tangential direction for the axial-symmetric state and the changes of two other displacements in this direction are: ${ }^{12}$

$$
u_{\theta}=0, \quad \frac{\partial u_{r}}{\partial \theta}=0, \quad \frac{\partial u_{z}}{\partial \theta}=0
$$

The stress tensor for the axial-symmetric deformation state is:

$$
T_{\varepsilon}=\left|\begin{array}{ccc}
\varepsilon_{r} & 0 & \frac{1}{2} \gamma_{r z} \\
0 & \varepsilon_{\theta} & 0 \\
\frac{1}{2} \gamma_{r z} & 0 & \varepsilon_{z}
\end{array}\right|
$$

The components of the strain tensor are:

$$
\left.\begin{array}{ll}
\varepsilon_{r}=\frac{\partial u_{r}}{\partial r} & \gamma_{r \theta}=0 \\
\varepsilon_{\theta}=\frac{u_{r}}{r} & \gamma_{\theta z}=0 \\
\varepsilon_{z}=\frac{\partial u_{z}}{\partial z} & \gamma_{r z}=\frac{\partial u_{r}}{\partial z}+\frac{\partial u_{z}}{\partial r}
\end{array}\right\}
$$

The effective strain is:

$$
\varepsilon_{e}=\frac{\sqrt{2}}{3} \sqrt{\left(\varepsilon_{r}-\varepsilon_{\theta}\right)^{2}+\left(\varepsilon_{\theta}-\varepsilon_{z}\right)^{2}+\left(\varepsilon_{r}-\varepsilon_{z}\right)^{2}+3 / 2 \gamma_{r z}^{2}}
$$

\subsection{Strain rates}

Analogously with the previous tensor, the tensor of strain rates for the axial-symmetric state is: ${ }^{12}$

$$
T_{\dot{\varepsilon}}=\left|\begin{array}{ccc}
\dot{\varepsilon}_{x} & \frac{1}{2} \dot{\gamma}_{x y} & \frac{1}{2} \dot{\gamma}_{x z} \\
\frac{1}{2} \dot{\gamma}_{x y} & \dot{\varepsilon}_{y} & \frac{1}{2} \dot{\gamma}_{y z} \\
\frac{1}{2} \dot{\gamma}_{x z} & \frac{1}{2} \dot{\gamma}_{y z} & \dot{\varepsilon}_{z}
\end{array}\right|
$$

The components of the strain-rate tensor in a cylindrical coordinate system, on the basis of ${ }^{8}$, are:

$$
\left.\begin{array}{l}
\dot{\varepsilon}_{r}=\frac{\partial v_{r}}{\partial r} \quad \dot{\gamma}_{r \theta}=0 \\
\dot{\varepsilon}_{\theta}=\frac{v_{r}}{r} \quad \dot{\gamma}_{\theta z}=0 \\
\dot{\varepsilon}_{z}=\frac{\partial v_{z}}{\partial z} \quad \dot{\gamma}_{z r}=\frac{\partial v_{r}}{\partial z}+\frac{\partial v_{z}}{\partial r}
\end{array}\right\}
$$

The effective strain rate is:

$\dot{\varepsilon}_{e}=\frac{\sqrt{2}}{3} \sqrt{\left(\dot{\varepsilon}_{r}-\dot{\varepsilon}_{\theta}\right)^{2}+\left(\dot{\varepsilon}_{\theta}-\dot{\varepsilon}_{z}\right)^{2}+\left(\dot{\varepsilon}_{r}-\dot{\varepsilon}_{z}\right)^{2}+3 / 2 \dot{\gamma}_{r z}^{2}}$

In the cylindrical coordinate system for the axialsymmetric state, the equations by Levy-Mises are as follows:

$$
\left.\begin{array}{l}
\dot{\varepsilon}_{z}=\lambda^{\prime}\left(\sigma_{z}-\sigma_{s r}\right)=\frac{\partial v_{z}}{\partial z} \\
\dot{\varepsilon}_{\theta}=\lambda^{\prime}\left(\sigma_{\theta}-\sigma_{s r}\right)=\frac{v_{r}}{r} \\
\dot{\varepsilon}_{r}=\lambda^{\prime}\left(\sigma_{r}-\sigma_{s r}\right)=\frac{\partial v_{r}}{\partial r} \\
\dot{\gamma}_{r z}=2 \lambda^{\prime} \tau_{r z}=\frac{\partial v_{r}}{\partial z}+\frac{\partial v_{z}}{\partial r}
\end{array}\right\}
$$

The coefficient of proportionality of $\lambda^{\prime}$ in ${ }^{13}$ is:

$$
\lambda^{\prime}=\frac{3}{2} \frac{\dot{\varepsilon}_{e}}{\sigma_{e}}
$$

\section{EQUATION OF VISIOPLASTICITY}

By combining of first two equations from Equation (13) the following can be written:

$$
\dot{\varepsilon}_{z}-\dot{\varepsilon}_{r}=\lambda^{\prime}\left(\sigma_{z}-\sigma_{r}\right)
$$

which gives the following:

$$
\sigma_{z}=\frac{\dot{\varepsilon}_{z}-\dot{\varepsilon}_{r}}{\lambda^{\prime}}+\sigma_{r}
$$

By differentiating the above equation with respect to $r$ for constant $\mathrm{z}$ and $\theta$ we obtain the following: 
M. JANJIĆ et al.: LOAD DETERMINATION BY ANALYSING THE STRESS STATE FOR THE OPEN-DIE FORGING ...

$$
\frac{\partial \sigma_{z}}{\partial r}=\frac{\partial \sigma_{r}}{\partial r}+\frac{\partial}{\partial r} \cdot\left(\frac{\dot{\varepsilon}_{z}-\dot{\varepsilon}_{r}}{\lambda^{\prime}}\right)
$$

From the first system balance equation (2) we obtain the following:

$$
\frac{\partial \sigma_{r}}{\partial r}=-\frac{\sigma_{r}-\sigma_{\theta}}{r}-\frac{\partial \tau_{z r}}{\partial z}
$$

while from the second and third equations the relation of the stress and strain rates of the system can be obtained (13):

$$
\begin{gathered}
\sigma_{r}=\frac{\dot{\varepsilon}_{r}}{\lambda^{\prime}}-\sigma_{s r} \\
\sigma_{\theta}=\frac{\dot{\varepsilon}_{\theta}}{\lambda^{\prime}}-\sigma_{s r}
\end{gathered}
$$

Substituting (19) into (17) we obtain:

$$
\frac{\partial \sigma_{r}}{\partial r}=\left(\frac{\dot{\varepsilon}_{\theta}-\dot{\varepsilon}_{r}}{\lambda^{\prime} r}\right)-\frac{\partial \tau_{s r}}{\partial z}
$$

If the above expression is replaced into equation (17) we obtain the following expression:

$$
\frac{\partial \sigma_{z}}{\partial r}=-\frac{\dot{\varepsilon}_{z}-\dot{\varepsilon}_{\theta}}{\lambda^{\prime}}-\frac{\partial \tau_{z r}}{\partial z}+\frac{\partial}{\partial r}\left(\frac{\dot{\varepsilon}_{z}-\dot{\varepsilon}_{r}}{\lambda^{\prime}}\right)
$$

Since from the fourth equation of the Levy-Mises system (13):

$$
\tau=-\frac{\dot{\gamma}_{r z}}{2 \lambda^{\prime}}
$$

then equation (21) takes the following shape:

$$
\frac{\partial \sigma_{z}}{\partial r}=\frac{\partial}{\partial r}\left(\frac{\dot{\varepsilon}_{z}-\dot{\varepsilon}_{r}}{\lambda^{\prime}}\right)-\frac{\dot{\varepsilon}_{z}-\dot{\varepsilon}_{\theta}}{\lambda^{\prime} r}-\frac{\partial}{\partial z}\left(\frac{\dot{\gamma}_{r}}{2 \lambda^{\prime}}\right)
$$

Substituting Equation (14) for $\lambda^{\prime}$ into equation (23) we obtain:

$$
\frac{\partial \sigma_{z}}{\partial r}=\frac{2}{3} \sigma_{e} \frac{\partial}{\partial r}\left(\frac{\dot{\varepsilon}_{z}-\dot{\varepsilon}_{r}}{\dot{\varepsilon}_{e}}\right)-\frac{\dot{\varepsilon}_{r}-\dot{\varepsilon}_{\theta}}{r \dot{\varepsilon}_{e}}-\frac{1}{2} \frac{\partial}{\partial z}\left(\frac{\dot{\gamma}_{z r}}{\dot{\varepsilon}_{e}}\right)
$$

Equation (24) represents the gradient of an axial stress, which depends on the strain rates and the effective stress at every point of the deformation zone. This is the basic equation of visioplasticity.

The components of the strain rates and the effective stress are determined experimentally so as to, using the defined mathematical operations via Equation (24), obtain the value of an axial stress in the relevant points of a deformable body volume. The only point where the axial stress cannot be determined is for $r=0$, because Equation (24) becomes undefined. However, because of the process symmetry at this point, the following applies:

$$
\frac{\partial \sigma_{z}}{\partial r}=0
$$

From the above it can be seen that the problem of determining the axial component of stress in the process of the axial-symmetric deformation is reduced to the problem of determining the components of the strain rates, the effective stress and the effective strain in the deformation zone.

With knowledge of the axial stress at each point of body volume, it is easy to obtain other components of the stress using the Levy-Mises equations (13):

$$
\begin{aligned}
\sigma_{r} & =\sigma_{z}+\frac{2}{3} \sigma_{e}\left(\frac{\dot{\varepsilon}_{r}-\dot{\varepsilon}_{z}}{\dot{\varepsilon}_{e}}\right) \\
\sigma_{\theta} & =\sigma_{z}+\frac{2}{3} \sigma_{e}\left(\frac{\dot{\varepsilon}_{\theta}-\dot{\varepsilon}_{z}}{\dot{\varepsilon}_{e}}\right) \\
\tau_{r s} & =\frac{\sigma_{e}}{3} \frac{\dot{\gamma}_{r z}}{\dot{\varepsilon}_{e}}
\end{aligned}
$$

\section{STUDY TOPIC}

The research was carried out in laboratory conditions, which were adjusted to be as similar as possible to the manufacturing conditions. ${ }^{7,8}$

The staggered axial-symmetric processing body with two levels of height from upper and one level on the lower partition plane is adopted (Figure 1).

Aluminium alloy AlMgSi0.5, the chemical composition of which is given in Table $\mathbf{1}$, is used as a test material.

Table 1: Chemical composition AlMgSi0.5 in mass fractions (w/\%) Tabela 1: Kemijska sestava AlMgSi0,5, v masnih odstotkih (w/\%)

\begin{tabular}{|c|c|c|c|c|c|c|c|c|c|}
\hline $\mathrm{Fe}$ & $\mathrm{Si}$ & $\mathrm{Ti}$ & $\mathrm{Cu}$ & $\mathrm{Zn}$ & $\mathrm{V}$ & $\mathrm{Cr}$ & $\mathrm{Mn}$ & $\mathrm{Mg}$ & $\mathrm{Ni}$ \\
\hline 0.207 & 0.477 & 0.01 & 0.09 & 0.068 & 0.004 & 0.01 & 0.1 & 0.493 & 0.02 \\
\hline
\end{tabular}

The testing is carried out at the hot processing temperature: $\mathrm{T}=440{ }^{\circ} \mathrm{C}$. The deformation is accomplished with a constant velocity: $v=2 \mathrm{~mm} / \mathrm{s}$. Graphite grease is used for the lubrication.

The experiment is carried out on the machine for the static testing with a hydraulic drive.

The upper and lower dies are used as tools (Figure 1), located in a slideway, which ensures their coaxiality

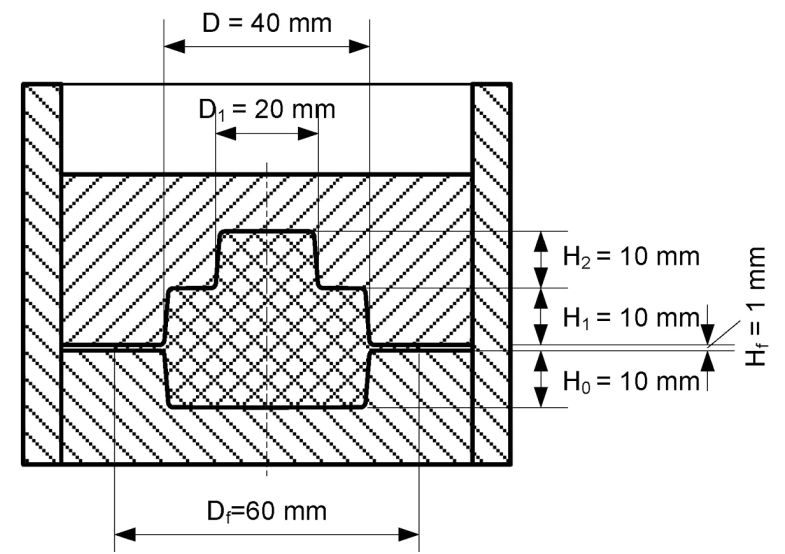

Figure 1: System: tools workpiece Slika 1: Sistem: orodje-obdelovanec 
and has the role of a chamber for the maintenance of a constant temperature. The slideway is heated together with the die and the specimens.

The dies are made of tool steel for work in hot state designated by X38CrMoV-5-1. ${ }^{13}$

The specimen dimensions are: $\varnothing d_{0} \times h_{0}=33 \times 33,94$ $\mathrm{mm}$. The specimen's height is calculated from the condition of volume constancy.

\section{DETERMINATION OF THE STRESS STATE}

\subsection{Determination of kinematic field using the speci- men volume}

The basis for the determination of a stress state using the visioplasticity method is the familiarity of the kinematic field. Two kinds of process can be differentiated: ${ }^{10}$

- stationary (drawing, milling, direct extrusion),

- non-stationary (opposite extrusion, squeezing in open dies).

For stationary processes, it is characteristic that the elements of the kinematic and stress fields in one unmovable point of space where the process is carried out are independent of time. Therefore, the kinematic field can be determined experimentally in any time (phase). Also, the duration of the phase is also not important under the assumption of the constant strain rate. For the non-stationary processes, the kinematic and stress fields in one unmovable space point where the deformation is carried out, are changed over time. In such a processes, the analyses of one defined increment of deformation cannot give an image about the kinematic and stress field for the entire process time, but only for the observed increment. Therefore, it is necessary to determine the interval (phase) at the end of which the stress state can be determined in the specimen volume.

The determination of the kinematic field necessary for solving the basic equation of visioplasticity (24) is carried out experimentally. It is possible to determine the components of the displacement velocities on the basis of the measured values of the displacements of the meridian cross-section points according to ${ }^{7,8}$ :

$$
\left.\begin{array}{l}
v_{r}=\frac{\Delta u_{r}}{\Delta t} \\
v_{z}=\frac{\Delta u_{z}}{\Delta t}
\end{array}\right\}
$$

The constant deformation state is the assumption for such a method of determination.

The displacements of the points in the radial and axial directions are determined on the basis of known numerical value coordinates of the mesh nodes (Figure 2):

$$
\left.\begin{array}{l}
u_{r}=r-r_{0} \\
u_{z}=z-z_{0}
\end{array}\right\}
$$

where:

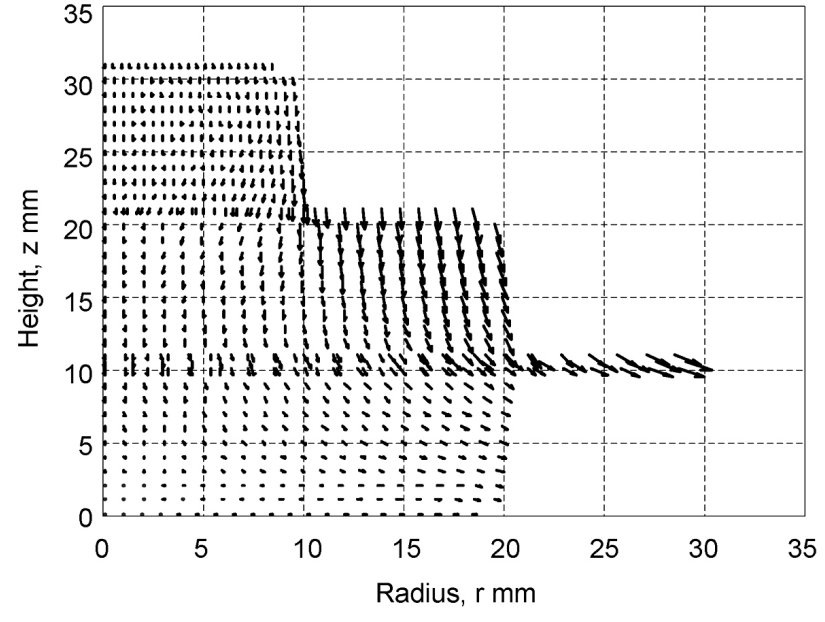

Figure 2: Displacements of cross-section points of the deformed mesh Slika 2: Premiki točk preseka v deformirani mreži

$u_{\mathrm{r}}, u_{\mathrm{z}}$ are the displacements in radial and axial directions at the end of the process,

$r, z$ are the coordinates of node points at the end of the process,

$r_{0}, z_{0}$ are the coordinates of node points at the start of the process.

In this way it is possible to determine the partial derivations of displacements using the radius, serving to obtain the deformation values. ${ }^{8,9}$

The determination of the displacement velocity represents the basis of the kinematic analysis. Since the deformation process in an open die is a non-stationary process, the displacement velocities are determined on the basis of the displacements of points at the start and at the end of a finite interval of the deformation at the end of the deformation process, under the assumption of a constant deformation velocity. This interval must be small enough to represent the true state of the displacement velocities, but not too small so as to avoid the impact of the anisotropy of deformation. Based on the preliminary experiments, it was proved that the optimal interval of deformation at the end of the process for the increment of a tool step of $\Delta z=2 \mathrm{~mm} .{ }^{14}$

At the beginning of the adopted interval, it was necessary to determine the deformed mesh of the specimen's radial cross-section. The deformation process is stopped at the flash height of $h_{\mathrm{f}}=3 \mathrm{~mm}$. The process of preparation of the specimen's cross-section, and the measurement of the lines of the deformed mesh is the same as for the determination of the deformations.

On the basis of the known values of the nodal point coordinates in the deformed and non-deformed mesh at the start of the observed interval, the displacements of the points in the radial and axial directions are determined:

$$
\left.\begin{array}{l}
u_{r a}=r_{a}-r_{0} \\
u_{z a}=z_{a}-z_{0}
\end{array}\right\}
$$

where: 
$u_{\mathrm{ra}}, u_{\mathrm{za}}$ are the displacements in the radial and axial directions at the start of the observed deformation interval, and $r_{\mathrm{a}}, z_{\mathrm{a}}$ are the coordinates of the nodal points at the start of the observed deformation interval.

The increase of the displacements in the nodal points of the deformed mesh is calculated as the difference in the displacements at the end and the start of the observed interval:

$$
\left.\begin{array}{l}
\Delta u_{r a}=u_{r}-u_{r a}=r-r_{a}=\Delta r \\
\Delta u_{z}=u_{z}-u_{z a}=z-z_{a}=\Delta z
\end{array}\right\}
$$

where: $\Delta u_{\mathrm{r}}, \Delta u_{\mathrm{z}}$ are the increments of displacements in radial and axial direction, and $\Delta r, \Delta z$ are the increments of the coordinates.

Having in mind that the deformation velocity is constant at $v=2 \mathrm{~mm} / \mathrm{s}$, and for the adopted tool step increment $\Delta z=2 \mathrm{~mm}$ the time increment is:

$$
\Delta t=\frac{\Delta z}{v} s
$$

It is possible to determine the components of the displacement velocity (27) on the basis of the values of the displacements of nodal points in the deformed mesh of the meridian cross-section (Figure 3):

$$
\left.\begin{array}{l}
v_{r}=\frac{\Delta u_{r}}{\Delta t}=\frac{\Delta r}{\Delta t} \\
v_{z}=\frac{\Delta u_{z}}{\Delta t}=\frac{\Delta z}{\Delta t}
\end{array}\right\}
$$

where: $v_{\mathrm{r}}, v_{\mathrm{z}}$ are the displacement velocities in the radial and axial directions.

Using the knowledge of the kinematic field, i.e., the distribution of displacement velocities, it is possible to determine the displacement velocities for the points of the meridian cross-section according to ${ }^{11}$, while the effective strain rate is determined using Equation (12). The partial derivations are determined for the small

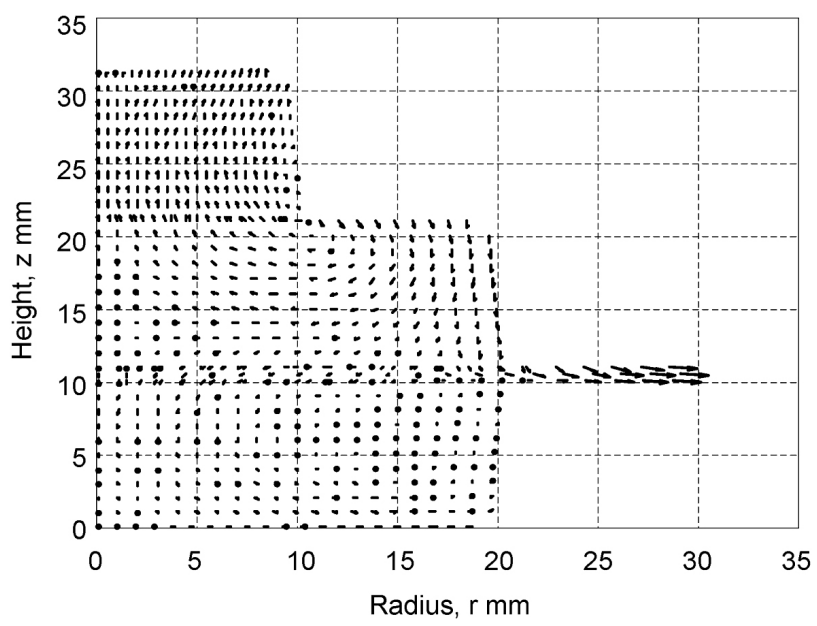

Figure 3: Vectors of the displacement velocities at certain points of the cross-section

Slika 3: Vektorji hitrosti premika določenih točk na preseku enough values $\Delta r, \Delta z$ and $\Delta t$ on the basis of the following Equations (33), (34) and (35):

$$
\begin{gathered}
\frac{\partial v_{r}}{\partial r}=\frac{\Delta v_{r}}{\Delta r} \\
\frac{\partial v_{z}}{\partial z}=\frac{\Delta v_{z}}{\Delta z} \\
\frac{\partial v_{r}}{\partial z}+\frac{\partial v_{z}}{\partial r}=\frac{\Delta v_{r}}{\Delta z} \frac{\Delta v_{z}}{\Delta z}
\end{gathered}
$$

\subsection{Determination of the stress components}

The distribution of an axial stress $\sigma_{z}$ in planes $z=$ const. is obtained by the integration of the basic visioplasticity Equation (24):

$\sigma_{z}=\int_{0}^{r} \frac{2}{3} \sigma_{e}\left[\frac{\partial}{\partial r}\left(\frac{\dot{\varepsilon}_{z}-\dot{\varepsilon}_{r}}{\dot{\varepsilon}_{e}}\right)-\left(\frac{\dot{\varepsilon}_{r}-\dot{\varepsilon}_{\theta}}{r \dot{\varepsilon}_{e}}\right)-\frac{1}{2} \frac{\partial}{\partial z}\left(\frac{\dot{\gamma}_{z r}}{\dot{\varepsilon}_{e}}\right)\right] \mathrm{d} r+C_{1}$

To obtain the absolute values of the axial stresses, it is necessary to determine the integral constant $C_{1}$. From the first equation of the system (26) it is necessary to obtain an expression for an axial stress at each point of the deformation zone as in the following Equation (37):

$$
\sigma_{z}=\sigma_{r}-\frac{2}{3} \sigma_{e}\left(\frac{\dot{\varepsilon}_{r}-\dot{\varepsilon}_{z}}{\dot{\varepsilon}_{e}}\right)
$$

The radial stress $\sigma_{\mathrm{r}}$ is not known for the complete deformation zone, but in the free area in the flash cross-section it is equal to zero, which means that the axial stress can be determined in that cross-section. If the first term from Equation (36) for a axial stress is designated with $\Delta \sigma_{z}$, the following Equation (38) can be written:

$$
\sigma_{z}=\Delta \sigma_{z}+C_{1}
$$

The integral constant at the point of the free area at the end of the flash can be obtained in the following way:

$$
C_{1}=\sigma_{z}\left|\left(\begin{array}{l}
z=z_{f} \\
r=r_{f}
\end{array}\right)-\Delta \sigma_{z}\right|\left(\begin{array}{l}
z=z_{f} \\
r=r_{f}
\end{array}\right)
$$

On the basis of known values $\sigma_{\mathrm{z}}$, the values of other components of the stress tensor can be obtained from Equation (26).

\subsection{Solving the basic visioplasticity equation}

The method is based on a calculation of the axial stress component $\sigma_{z}$ by solving the basic visioplasticity Equation (24), where the main problem is the determination of integral constant $C_{1}$ (Equation (36)). Having in mind that the integration of the visioplasticity equation is done with a radius, the value of the axial stress component at one point of radius $r$ for a particular value of the height y must be known in order to determine the integral constant $C_{1}$. The only points where it is possible 
M. JANJIĆ et al.: LOAD DETERMINATION BY ANALYSING THE STRESS STATE FOR THE OPEN-DIE FORGING ...

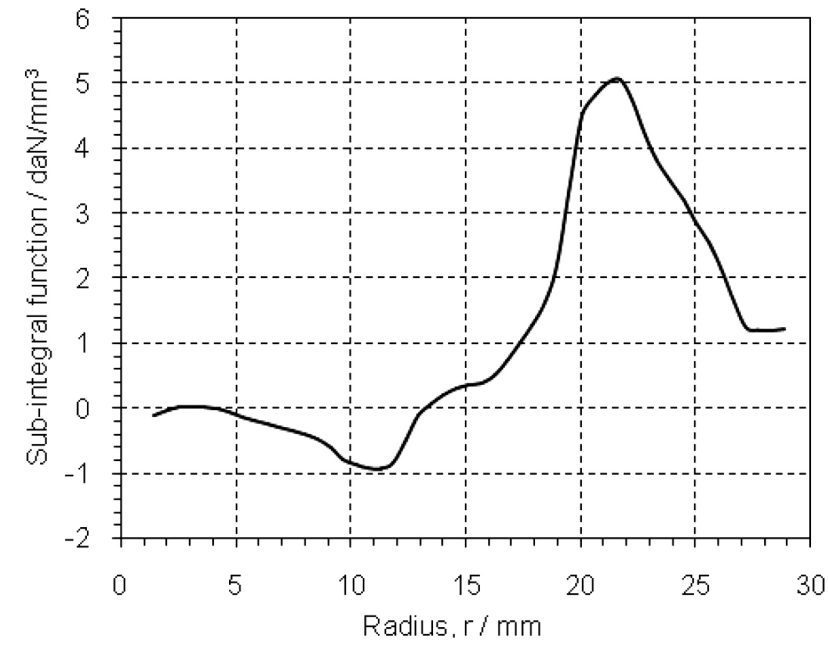

Figure 4: Sub-integral function of the visioplasticity equation for the cross-section of the partition plane

Slika 4: Podintegralna funkcija enačbe vizioplastičnosti na preseku delilne ravnine

to determine the value of the axial stress component are the points for the maximum values of the radius on the flash level (Figure 1). These values are determined on the basis (37) form the condition that the radial stress component in these points is equal to zero: $\sigma_{\mathrm{r}}=0$. Other deformation kinematic parameters are known, where the effective stress is determined from the corresponding curved strengthening for the value of the effective strain.

The value of the sub-integral function of Equation (36) is known because all the strain and kinematic parameters and the effective stress are known, and they are presented in Figure 4. Using the integration of this function on $r$, the indefinite integral given in Figure $\mathbf{5}$ is obtained, and the integral constant is determined in a previously described way.

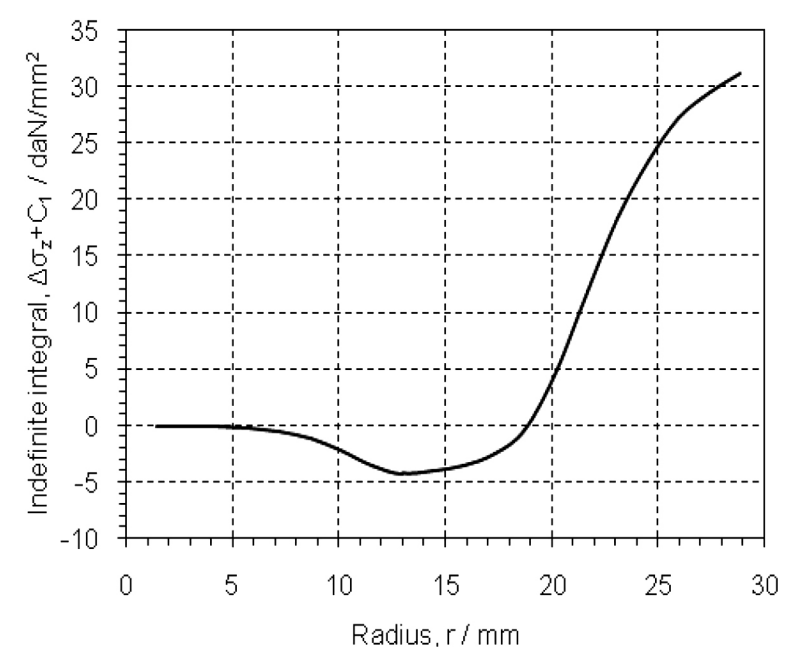

Figure 5: Undefined integral of the visioplasticity equation $\Delta \sigma_{\mathrm{z}}+C_{1}$ at the cross-section of the partition plane

Slika 5: Nedoločeni integral enačbe vizioplastičnosti $\Delta \sigma_{\mathrm{z}}+C_{1}$ na preseku delilne ravnine

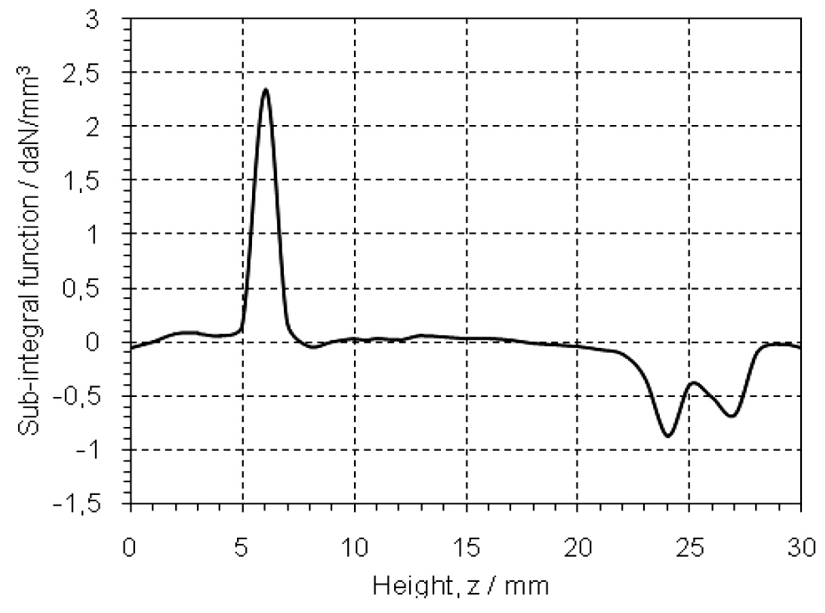

Figure 6: Sub-integral function of the second equation for the specimen's axis

Slika 6: Podintegralna funkcija druge enačbe za os vzorca

The integral constant is impossible to determine because of the unknown radial stress at other points. For this reason, on the basis of the system balance Equation (2), it follows that:

$$
\sigma_{z}=\int_{0}^{z}\left(\frac{\partial \tau_{r z}}{\partial r}+\frac{\tau_{r z}}{r}\right) \mathrm{d} z+C_{2}
$$

If the first term of the previous expression is marked with $\Delta \sigma_{\mathrm{z} 0}$, then the following can be written:

$$
\left.\sigma_{z}\right|_{\left(\begin{array}{c}
z=z_{f} \\
r=0
\end{array}\right)}=\left.\Delta \sigma_{z}\right|_{\left(\begin{array}{c}
z=z_{f} \\
r=0
\end{array}\right)}+C_{2}
$$

and so:

$$
C_{2}=\sigma_{z}\left|\left(\begin{array}{c}
z=z_{f} \\
r=0
\end{array}\right)-\Delta \sigma_{z 0}\right|\left(\begin{array}{c}
z=z_{f} \\
r=0
\end{array}\right)
$$

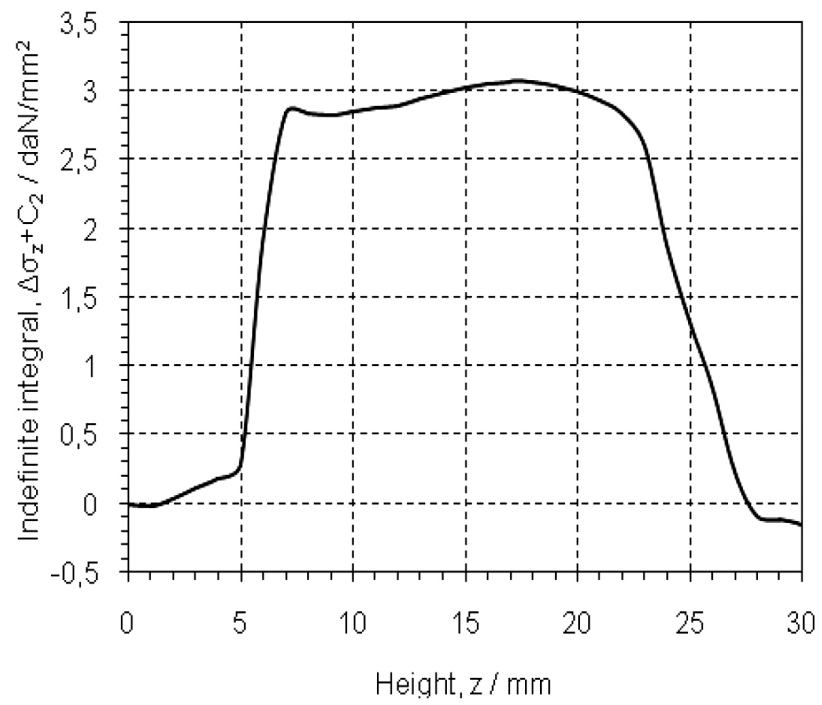

Figure 7: Indefinite integral of the second balance equation $\Delta \sigma_{z 0}+C_{2}$ in the specimen's axis

Slika 7: Nedoločni integral druge ravnotežne enačbe $\Delta \sigma_{z 0}+C_{2}$ na osi vzorca 
M. JANJIĆ et al.: LOAD DETERMINATION BY ANALYSING THE STRESS STATE FOR THE OPEN-DIE FORGING ...

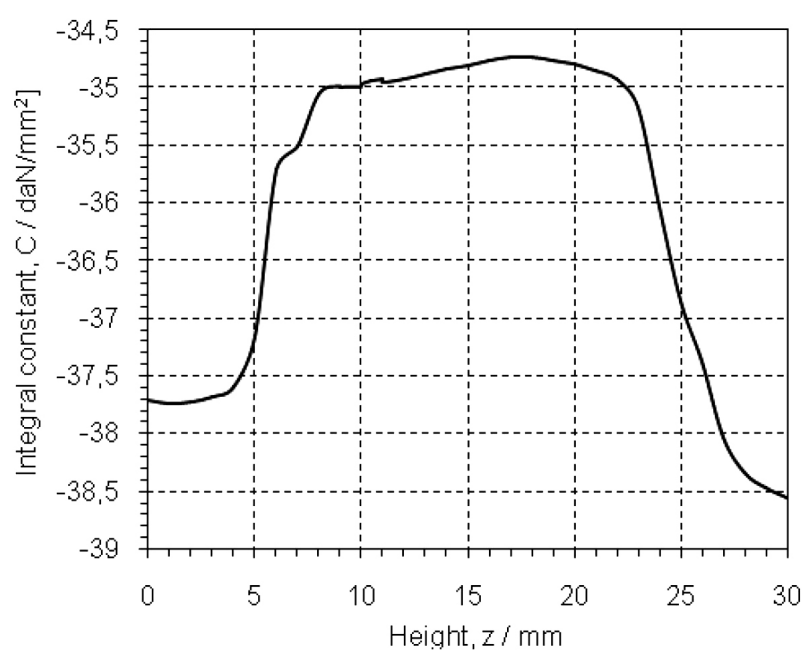

Figure 8: Integral constant $C$ as a function of the height $z$ Slika 8: Konstanta integrala $C$ v funkciji višine $z$

In this way, all the values of the axial stress component in the axis of the specimen's symmetry are obtained, i.e., $r=0 \mathrm{~mm}$, which actually represents the possibility for a determination of the integral constant for all the values of the height $z$.

The values of the sub-integral function (40) as a function of the height are given at Figure 6, and the values of indefinite integral for $r=0 \mathrm{~mm}$ in Figure 7 .

The integral constant is determined on the basis of:

$$
\left.\sigma_{z}\right|_{\left(\begin{array}{c}
z \\
r=0
\end{array}\right)}=\Delta \sigma_{z} \mid\left(\begin{array}{c}
z \\
r=0
\end{array}\right)+C
$$

and so:

$$
C=\sigma_{z}\left|\left(\begin{array}{l}
z \\
r=0
\end{array}\right)-\Delta \sigma_{z 0}\right|\left(\begin{array}{l}
z \\
r=0
\end{array}\right)
$$

which is graphically represented in Figure 8 as a function of the height $z$.

The values of the normal stress at all the points of the specimen's meridian cross-section are obtained in the

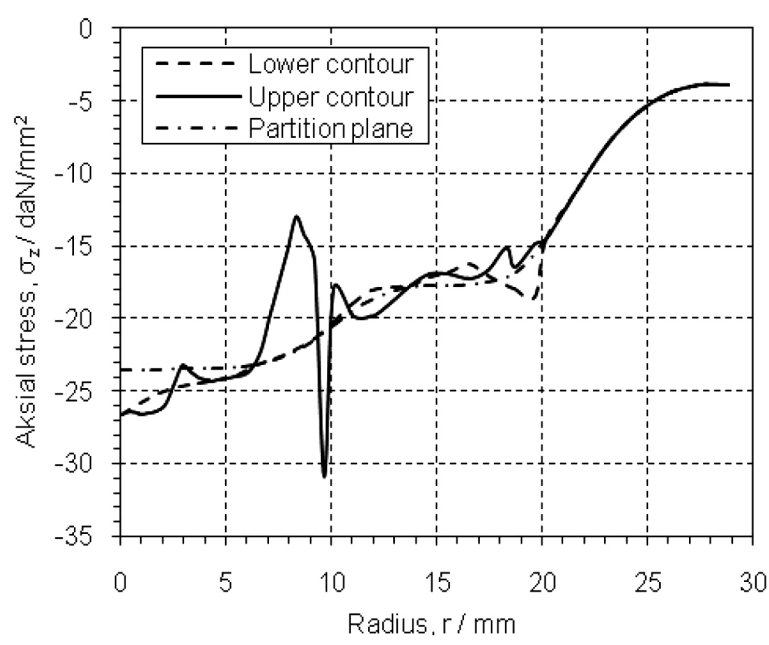

Figure 9: Axial stress $\sigma_{\mathrm{z}}$ Slika 9: Napetost v osi $\sigma_{\mathrm{z}}$

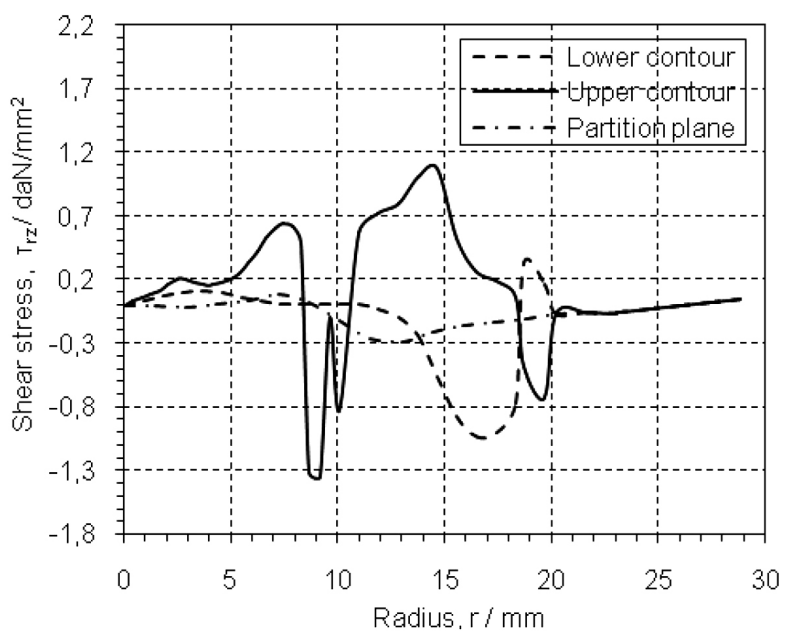

Figure 10: Shear stress $\tau_{\mathrm{rz}}$

Slika 10: Strižna napetost $\tau_{\mathrm{rz}}$

previously described way, and other tensor components are determined on the basis of relations (26). The values of the axial and shear stress using the upper and lower contour of the specimen's contour, and in the cross-section of the partition plane, are given in Figure 9 and Figure 10.

MATLAB has developed the program for a determination of all the stress parameters for the specimen's cross-section using the visioplasticity method, all numerical integrations and for the determination of the integral constants. As the entry data, besides the curve of strengthening and the geometrical parameters, the program uses the output results from the strain and kinematic analyses.

\section{DEFORMATION FORCE}

The familiarity with the stress state in the specimen's meridian plane enables the determination of deformation force. Also, this value, in a relatively simple way, can be experimentally measured with a high accuracy and can be used for an estimation of the accuracy of the stress deformation analysis. In this case it is the z-axis direction and the stress components that are the axial and shear stress. The deformation force is calculated as a sum of the integrals using the area of change of the mentioned stress components: ${ }^{12}$

$$
F_{m}=\int_{A} \sigma_{z} \mathrm{~d} A+\int_{A} \tau_{r z} \mathrm{~d} A
$$

Figure 11 presents the experimentally obtained deformation forces during the process and the values of the forces at the end of the deformation process calculated using the visioplasticity method on the basis of the determined stress state for the upper contour, the lower contour and the cross-section of the partition plane. On the basis of the law of static balance of a body, the forces obtained for the upper and lower die should be the same; however, certain deflections emerge because of 
M. JANJIĆ et al.: LOAD DETERMINATION BY ANALYSING THE STRESS STATE FOR THE OPEN-DIE FORGING ...

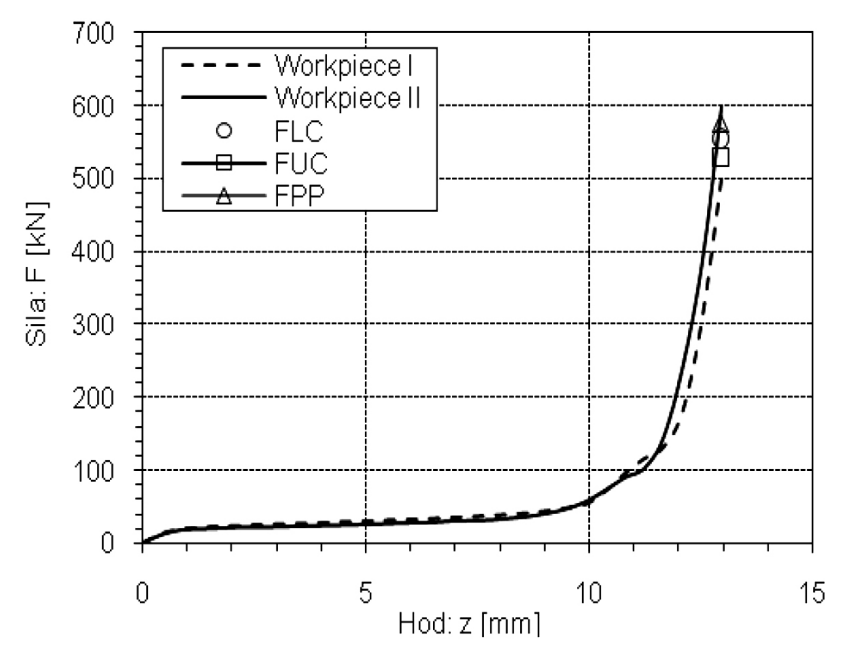

Figure 11: Deformation forces as a function of motion

Slika 11: Sile deformacije v odvisnosti od premika

the calculation errors. These deflections are relatively small, which indicates that the forces are determined with a satisfactory accuracy.

\section{CONCLUSION}

This paper deals with the stress state for the open-die forging process for an axial-symmetric specimen made of the aluminium alloy $\mathrm{AlMgSi0.5}$. The originally adjusted, experimental-theoretical visioplasticity method for the open-die forging.

The visioplasticity method consists of five steps. Using the basic equations of the plasticity theory, i.e., balance equation, condition of plastic flow, and LevyMises equation, enables the obtaining of the basic visioplasticity equation. The starting basis is made of experimentally determined displacements of the points of the meridian cross-section.

When solving the basic visioplasticity equation, the determination of the integral constant represents the main problem. It is calculated for the cross-section of the partition plane because an axial stress is known at the free end of the flash and it is equal to the flow stress. Then the axial stress along the specimen axis and integral constant on the basis of the known axial stress in the cross-section of partition plane and $\mathrm{z}$ axis. After this, an axial stress in all cross-sections is determined, and the integral constants on the basis of known values of the stress along the $\mathrm{z}$ axis.

The deformation force, as the sum of the integrals for the area of normal and shear stress for the upper contour, the lower contour and the cross-section of the partition plane, is obtained on the basis of the obtained results. The obtained values are: $F_{\mathrm{u}}=529 \mathrm{kN}, F_{1}=555 \mathrm{kN}, F_{\mathrm{p}}=$ $576 \mathrm{kN}$. The experimentally measured values at the end of the deformation process are: $F_{\mathrm{I}}=500.66 \mathrm{kN}$ in $F_{\mathrm{II}}=$ $600.35 \mathrm{kN}$. The deflections of the experimental values are in range of $16.61 \%$, and for the calculated values on the basis of the stress state obtained by the visioplasticity method $8.16 \%$, and they are between the minimum and maximum experimental values of the experimental values of the deformation force at the end of the process.

It can be concluded that the adapted visioplasticity model for the determination of the stress state for the open-die forging gives the results that overlap well with the experimental results, so that it can be applied to other families of axial-symmetry specimens made of different materials.

\section{Acknowledgements}

This work was carried out as a part of the research on the project: RTPPIMS\&NS, number: 01-376, funded by The Ministry of Science of Montenegro.

\section{APPENDIX}

$T_{\sigma} \quad$ stress tensor

$\sigma_{r} \quad$ radial normal stress

$\sigma_{z} \quad$ axial normal stress

$\sigma_{\theta} \quad$ tangential normal stress

$\tau_{r z}$ radial-axial shear stress

$\sigma_{e} \quad$ axial normal stress

$\sigma_{a}$ average normal stress

$u_{r}$ radial displacement

$u_{z}$ axial displacement

$u_{\theta} \quad$ tangential displacement

$T_{\varepsilon} \quad$ strain tensor

$\varepsilon_{r} \quad$ radial normal strain

$\varepsilon_{z} \quad$ axial normal strain

$\varepsilon_{\theta} \quad$ tangential normal strain

$\gamma_{r z}$ radial-axial shear strain

$\varepsilon_{e} \quad$ effective strain

$T_{\dot{\varepsilon}} \quad$ strain rate tensor

$\dot{\varepsilon}_{r} \quad$ radial strain rate

$\dot{\varepsilon}_{z} \quad$ axial strain rate

$\dot{\varepsilon}_{\theta} \quad$ tangential strain rate

$\dot{\gamma}_{r z}$ radial-axial strain rate

$\dot{\gamma}_{\theta}$ effective strain rate

$\lambda^{\prime} \quad$ coefficient of proportionality

$T$ temperature

$v$ deformation velocity

$d_{0} \quad$ diameter of specimen

$h_{0}$ height of specimen

$D$ basic diameter of workpiece

$D_{1} \quad$ diameter of second degree of workpiece

$D_{f}$ diameter of flash

$h_{f}$ height of flash

$H_{0}$ height of lower degree under the partition plane of workpiece

$H_{1}$ height of first degree above the partition plane of workpiece

$\mathrm{H}_{2}$ height of second degree above the partition plane of workpiece

$v_{r} \quad$ radial displacement velocity 
M. JANJIĆ et al.: LOAD DETERMINATION BY ANALYSING THE STRESS STATE FOR THE OPEN-DIE FORGING ...

$v_{z} \quad$ axial displacement velocity

$u_{r} \quad$ radial displacement

$u_{z}$ axial displacement

$r$ radial coordinate

$z \quad$ axial coordinate

$r_{0}$ radial coordinate at the start of the deformation process

$z_{0}$ axial coordinate at the start of the deformation process

$\Delta r$ radial increment

$\Delta z$ axial increment

$\Delta t$ time increment

$u_{r a}$ radial displacement at the start of the observed deformation interval

$u_{z a}$ axial displacement at the start of the observed deformation interval

$r_{a}$ radial coordinate at the start of the observed deformation interval

$z_{a}$ axial coordinate at the start of the observed deformation interval

$\Delta u_{r}$ radial increment of displacement

$\Delta u_{z}$ axial increment of displacement

$\mathrm{C}, \mathrm{C}_{1}, \mathrm{C}_{2}$ integral constants

$F_{m}$ maximum deformation force

$F_{u}$ deformation force for the upper contour of the workpiece

$F_{1}$ deformation force for the lower contour of the workpiece

$F p$ deformation force for the partition plane of workpiece

FI experimental measured deformation force for workpiece I

FII experimental measured deformation force for workpiece II

\section{REFERENCES}

${ }^{1}$ V. Mandic, D. Adamovic, Z. Jurkovic, M. Stefanovic, M. Zivkovic, S. Ranđelovic, T. Marinkovic, Numerical FE Modelling of the Ironing Process of Aluminium Alloy and its Experimental Verification, Transactions of FAMENA, 34 (2010) 4, 59-69

${ }^{2}$ P. Harley, I. Pillinger, Numerical simulation of the forging process, Computer Methods in Applied Mechanics and Engineering, 195 (2006) 48-49, 6676-6690, doi:10.1016/j.cma.2005.03.013

${ }^{3}$ V. Mandic, Physical and numerical modeling of deformation processing, University of Kragujevac - Faculty of Engineering Sciences, 2012, 27

${ }^{4} \mathrm{~J}$. Danckert, T. Wanheim, The use of a square grid as an alternative to a cirkular grid in the determination of strains, Journal of Mechanical Working Technology, 3 (1979), 5-15, doi:10.1016/0378-3804(79) 90028-7

${ }^{5}$ S. Alexandrov, An analysis of the Axisymmetric Compression of Viscous Materials, Journal of Material Processing Technology, 105 (2000) 3, 278-283, doi:10.1016/S0924-0136(00)00652-X

${ }^{6}$ R. Sowerby, E. Chu, J. L. Duncan, Determination of large strains in metal forming, Journal of Strain Analysis, 17 (1982) 2, 95-101

${ }^{7}$ M. Janjic, M. Vukcevic, N. Sibalic: Strain modelling at axi-symmetrical deformation process in open dies, Proc. of the $11^{\text {th }}$ International Research/Expert Conference: Trends in the Development of Machinery and Associated Technology, Hammamet, 2007, 115-118

${ }^{8}$ M. Janjic, S. Savicevic, M. Vukcevic, N. Sibalic: Experimental discretization for determination of strain state. http://www.meching.com/journal/Archive/2013/10/41_Janjic_mtm13.pdf, 01.10.2013

${ }^{9}$ M. Vukcevic, M. Janjic, V. Domazetovic: The influence of geometrical parameters in deforming of axys-symmetric workpieces in open dies, Proc. of the XXVI JUPITER Conference, Belgrade, 2000, 3.117-3.122

${ }^{10}$ M. Plancak, Stress-strain state in the processes of cold extrusion steel, Faculty of Technical Sciences, Novi Sad, 1984, 33

${ }^{11}$ L. Gusel, R. Rudolf, B. Kosec, Analysis of a strain rate field in cold formed material using the visioplasticity method, Metalurgija, 48 (2009) 2, 103-107

${ }^{11}$ B. Musafia, Applied theory of plasticity, University of Sarajevo, 1973, 13

${ }^{13}$ M. Plancak, D. Vilotic, Dies and tools for metal forming, Faculty of Technical Sciences, Novi Sad, 2011, 171

${ }^{14}$ M. Janjic, S. Savicevic, N. Sibalic: Analysis of kinematic state parameters by simulation and experimental method Proc. of the $16^{\text {th }}$ International Research/Expert Conference: Trends in the Development of Machinery and Associated Technology, Dubai, 2012, $535-538$ 